\title{
Aspectos clínico-patológicos do envenenamento botrópico experimental em equinos ${ }^{1}$
}

\author{
Melina Garcia de Sousa ${ }^{2 *}$, Carlos Hubinger Tokarnia ${ }^{3}$, Marilene de Farias Brito ${ }^{4}$, \\ Alessandra Belo Reis ${ }^{2}$, Carlos Magno Oliveira ${ }^{2}$, Nayra Fernanda Freitas ${ }^{2}$, \\ Cairo Henrique Oliveira ${ }^{2}$ e José Diomedes Barbosa ${ }^{2}$
}

\begin{abstract}
Sousa M.G., Tokarnia C.H., Brito M.F., Reis A.B., Oliveira C.M., Freitas N.F., Oliveira C.H. \& Barbosa J.D. 2011. [Clinical and pathological aspects of the experimental poisoning by Bothrops snakes in horses.] Aspectos clínico-patológicos do envenenamento botrópico experimental em equinos. Pesquisa Veterinária Brasileira 31(9):773-780. Central de Diagnóstico Veterinário, Universidade Federal do Pará, Rua Maximino Porpino da Silva 1000, Pirapora, Castanhal, PA 68743-080, Brazil. E-mail: Melina_garcia 19@hotmail.com

The clinical and pathological alterations in horses, experimentally inoculated with Bothropoides jararaca, Bothrops jararacussu, Bothrops moojeni and Bothropoides neuwiedi poisons, were studied with the purpose to supply subsidies for the diagnosis of the poisoning. The liofilized poisons were diluted in $1 \mathrm{ml}$ of physiologic solution and subcutaneously administered to six horses, at doses of 0.5 and $1 \mathrm{mg} / \mathrm{kg}$ (B. jararaca), 0.8 and $1.6 \mathrm{mg} / \mathrm{kg}$ (B. jararacussu), $0.205 \mathrm{mg} / \mathrm{kg}$ (B. moojeni) and $1 \mathrm{mg} / \mathrm{kg}$ (B. neuwiedi). All horses, less those that received the poison of B. jararacussu, died The clinical signs began between $8 \mathrm{~min}$ and $2 \mathrm{~h} 10 \mathrm{~min}$ after the inoculation. The clinical course varied, in the four cases of lethal exit, from $24 \mathrm{~h} 41 \mathrm{~min}$ to $70 \mathrm{~h} 41 \mathrm{~min}$, and was 16 days in the two horses that recovered,. The clinical picture, independent of the poison type and doses, was characterized by tumefaction at the site of inoculation, dragging on the ground with the hooves of the inoculated leg, inquietude, apathy, decrease of reaction to external stimuli, pale mucous membranes and hemorrhages. Laboratory exams revealed normocytic normochrômic anemia with progressive decrease in the number of erythrocytes, of hemoglobin and of the hematocrit, and leucocytosis due to neutrophilia. There was increase of alamina aminotransferase, creatinaquinase, lactic dehydrogenase, ureia and glucose, as well increase of the time of activation of protrombin and partial tromboplastina. At postmortem examination, the main findings were extensive hemorrhagic areas in the subcutaneous tissue, with the presence of non-coagulated blood, to a large degree associataed with edema (hemorragic edema), which extended from the inoculation site of the venom to the cervical, thoraxic and scapular region, and to the leg. In the periphery of the hemorragic areas existed gelatinous edema. There were great amounts of sanguinary liquid in the thoracic, pericardic and abdominal cavities. No significant histological alterations were found.
\end{abstract}

INDEX TERMS: Poisoning by Bothrops snakes, Bothrops spp., pathology, Equidae.

RESUMO.- Estudou-se as alterações clínico-patológicas e laboratoriais em equinos, inoculados experimentalmente com a peçonha de Bothropoides jararaca, Bothrops jararacussu,

\footnotetext{
${ }^{1}$ Recebido em 5 de maio de 2011.

Aceito para publicação em 29 de junho de 2011.

${ }^{2}$ Central de Diagnóstico Veterinário (Cedivet), Faculdade de Medicina Veterinária, Universidade Federal do Pará, Rua Maximino Porpino da Silva 1000, Castanhal, PA 68740-080, Brasil. *Autor para correspondência: Melina_garcia 19@hotmail.com

${ }^{3}$ Departamento de Nutrição e Pastagem, Instituto de Zootecnia, Universidade Federal Rural do Rio de Janeiro (UFRRJ), Seropédica, RJ 23890-000, Brasil..

${ }^{4}$ Departamento de Epidemiologia e Saúde Pública, Instituto de Veterinária, UFRRJ, Seropédica, RJ.
}

Bothrops moojeni e Bothropoides neuwiedi, com a finalidade de fornecer subsídios para o diagnóstico do envenenamento pela picada dessas. Os venenos liofilizados foram diluídos em $1 \mathrm{ml}$ de solução fisiológica e administrados a seis equinos, por via subcutânea, nas doses de 0,5 e $1 \mathrm{mg} / \mathrm{kg}$ (B. jararaca), 0,8 e $1,6 \mathrm{mg} / \mathrm{kg}$ (B. jararacussu), $0,205 \mathrm{mg} / \mathrm{kg}$ (B. moojeni) e $1 \mathrm{mg} / \mathrm{kg}$ (B. neuwiedi). Todos os equinos, menos os que receberam o veneno de B. jararacussu, morreram Os sinais clínicos iniciaram-se entre $8 \mathrm{~min}$ e $2 \mathrm{~h} 10 \mathrm{~min}$ após a inoculação. 0 período de evolução variou, nos quatro casos de êxito letal, de $24 \mathrm{~h} 41 \mathrm{~min}$ a $70 \mathrm{~h} 41 \mathrm{~min}$, e nos dois equinos que se recuperaram foi de 16 dias. 0 quadro clínico, independente do tipo de veneno e das doses, caracterizou-se por aumento de volume 
no local da inoculação, arrastar da pinça do membro inoculado no solo, inquietação, apatia, diminuição da resposta aos estímulos externos, mucosas pálidas e hemorragias. Os exames laboratoriais revelaram anemia normocítica normocrômica com progressiva diminuição no número de hemácias, da hemoglobina e do hematócrito, e leucocitose por neutrofilia. Houve aumento de alamina aminotransferase, creatinaquinase, dehidrogenase láctica, ureia e glicose, bem como aumento do tempo de ativação da protrombina e do tempo de tromboplastina parcial ativada. Os achados de necropsia foram extensas hemorragias no tecido subcutâneo, com presença de sangue não coagulado e em boa parte associadas a edema (edema hemorrágico), que se estendia desde o local da inoculação até as regiões cervical, torácica, escapular e membro. Na periferia das áreas hemorrágicas havia predominantemente edema gelatinoso. Havia ainda presença de grande quantidade de líquido sanguinolento nas cavidades torácica, pericárdica e abdominal. Não foram encontradas alterações histológicas significativas.

TERMOS DE INDEXAÇÃO: Envenenamento botrópico, equinos, Bothrops spp., patologia.

\section{INTRODUÇÃO}

Fazendeiros, vaqueiros e também veterinários de campo, acreditam que as picadas de cobra constituem uma causa muito frequente de morte em animais de fazenda, e que determinam grandes perdas econômicas aos pecuaristas. Em relação aos bovinos, Tokarnia \& Peixoto (2006) são da opinião que os acidentes ofídicos fatais em bovinos são bem menos frequentes do que se acredita, isto é, a sua importância vem sendo bastante superestimada.

Casos esporádicos de acidentes com serpentes dos gêneros Bothrops ${ }^{5}$ ocorrem em bovinos e equinos. Há poucos dados sobre o quadro clínico-patológico provocado pelo veneno dessas serpentes nos animais (Grunert \& Grunert 1969). Já foram realizados experimentos em bovinos, porém, sem muito detalhamento sobre o quadro clínico-patológico (Araújo et al. 1963, Novaes et al. 1986, Oliveira et al. 2004a,b, Oliveira et al. 2007). Contudo, somente Caldas et al. (2008) em bovinos, com B. alternatus, Aragão et al. (2010) em ovinos com B. jararaca e B. jararacussu, e Gomes (2011) em ovinos com B. moojeni e Bothropoides neuwiedi, descreveram, detalhadamente, os achados clínico-patológicos e laboratoriais do envenenamento experimental.

Esse estudo tem por objetivo descrever as alterações clínico-patológicos e laboratoriais em equinos inoculados experimentalmente com a peçonha de Bothropoides jararaca, Bothrops jararacussu, Bothrops moojeni e Bothropoides neuwiedi, com a finalidade de fornecer subsídios para o diagnóstico.

\section{MATERIAL E MÉTODOS}

0 experimento foi realizado no mês de fevereiro de 2010, nas instalações da propriedade Curicaca, no município de Castanhal, PA. Foram utilizados oito equinos, sendo seis machos e duas fêmeas, sem raça definida, provenientes do município de Tracuateua, PA, clinicamente sadios, adultos, com pesos entre 80 e $198 \mathrm{~kg}$, dentre os quais dois foram utilizados como controle. Os animais foram mantidos em piquetes com pastos de Brachiaria spp. e Panicum spp., com água à vontade, e foram tratados contra endo e ectoparasitos e adaptados ao local.

Os venenos liofilizados de Bothropoides jararaca, Bothrops jararacussu, provenientes do Instituto Vital Brazil, e Bothrops moojeni, Bothropoides neuwiedi, provenientes do Biotério da Universidade Católica Dom Bosco (UCDB), Campo, MS, foram colhidos pela extração manual, dessecados à vácuo e mantidos congelados a $10^{\circ} \mathrm{C}$ negativos, pesados em balança eletrônica de precisão e reconstituídos em $1 \mathrm{ml}$ de soro fisiológico no momento de sua utilização.

Os venenos foram inoculados nos equinos (Quadro 1), por via subcutânea, no membro anterior esquerdo, à altura da articulação úmero-rádio-ulnar. Os equinos controle receberam $1 \mathrm{ml}$ de solução fisiológica, inoculada pela mesma via e local de aplicação dos demais. 0 delineamento experimental consta no Quadro 1.

Após a inoculação do veneno, os equinos foram acompanhados clinicamente a cada duas horas até o óbito, ou até o desaparecimento dos sinais clínicos. Foram realizadas colheitas de sangue por venopunção da jugular para realização de hemograma, bioquímica sérica e coagulograma de cada animal, nos tempos $0,2,6,12,24$, 48 e 72 horas após a inoculação; decorridas 72 horas nos animais que sobreviveram foram realizadas colheitas a cada 24 horas até a recuperação total do animal. As amostras de sangue destinadas à bioquímica sérica foram colhidas em frascos que permitiram a formação e retração do coágulo, com exceção daquelas destinadas ao coagulograma, as quais foram colocadas em frascos com anticoagulante protrombina (Doles ${ }^{\circledR}$ ). As amostras destinadas à realização de hemograma foram colhidas em frascos com ácido etilenodiaminotetra-acético (EDTA) a 10\%. Para a dosagem de glicose sanguínea foi utilizado um glicosímetro (Glicosímetro Accucheck $^{\circledR}$ Active - Roche).

As amostras de sangue foram colocadas sob refrigeração e enviadas para o Laboratório de Patologia Clínica da Universidade Federal do Pará para processamento; as amostras contendo anticoagulante protrombina foram processadas no laboratório Center Lab em Castanhal, Pará. No hemograma foi avaliada a série vermelha (hematimetria, hematócrito, hemoglobina, CHGM, HGM, VGM) e a série branca (leucometria total e leucometria específica). Na bioquímica sérica foram dosados ureia, creatinina, cálcio, fósforo, magnésio, AST (aspartato aminotransferase), ALT (alamina aminotransferase), GGT (gama glutamiltransferase), fosfatase alcalina, bilirrubina direta, bilirrubina total, creatinaquinase (CK) e dehidrogenase láctica (DHL). Para realização destes exames foram utilizados kits comerciais (Bioclín ${ }^{\circledR}$, Cepa $^{\circledR}$, Doles ${ }^{\circledR}$ ) e as leituras foram realizadas em espectofotômetro (Bioplus, modelo Bio 2000). $\mathrm{Na}$ avaliação do coagulograma foram realizadas as seguintes análises: Tempo de ativação da protrombina (TAP), Tempo de tromboplastina parcial ativada (TTPA), utilizando-se kits comerciais (Laborlab ${ }^{\circledR}$ ).

As amostras de urina foram colhidas durante a micção natural e armazenadas em frascos estéreis. Foram realizadas análises químicas para determinação qualitativa e semiquantitativa de substâncias normalmente ausentes ou presentes apenas como vestígios; para isso foram utilizadas fitas reagentes (Uri Test 11 Inlab $^{\circledR}$ ).

As necropsias foram realizadas imediatamente após a morte dos animais. Foram colhidos encéfalo, medula, hipófise, fragmentos de coração, pulmões, fígado, rins, baço, estômago, intestinos, bexiga,

\footnotetext{
${ }^{5}$ De acordo com Melgarejo (2010) e a Sociedade Brasileira de Herpetologia (2010), houve modificações na nomenclatura de algumas serpentes. Por exemplo, Bothrops jararaca passou a denominar-se Bothropoides jararaca, Bothrops neuwiedi agora se denomina Bothropoides neuwiedi. Enquanto que, Bothrops jararacussu e Bothrops moojeni manteve a mesma denominação. Já Bothrops alternatus agora é designada por Rhinocerophis alternatus e Crotalus durissus por Caudisona durissa.
} 
adrenal, pâncreas, pele com tecido subcutâneo e músculos do local da inoculação, e imediatamente fixados em formol a 10\%, com exceção dos fragmentos de músculos, que foram fixados após duas horas.

Os fragmentos foram submetidos ao processamento de rotina para histopatologia, cortados a 5ì e corados pela hematoxilina e eosina (HE), no Setor de Anatomia Patológica do Projeto Sanidade Animal, Universidade Federal Rural do Rio de Janeiro.

\section{RESULTADOS}

Os principais dados do experimento encontram-se no Quadro 1.

\section{Dose letal e evolução}

A peçonha de Bothropoides jararaca, nas doses de 0,5 e $1 \mathrm{mg} / \mathrm{kg}$ causou a morte dos equinos, com evolução de $24 \mathrm{~h} 41 \mathrm{~min}$ e $59 \mathrm{~h} 7 \mathrm{~min}$, respectivamente. Em relação a $B o-$ throps jararacussu, as doses de 0,8 e $1,6 \mathrm{mg} / \mathrm{kg}$ determinaram quadros não fatais do envenenamento, com período de evolução de 16 dias. Na dose de $0,205 \mathrm{mg} / \mathrm{kg}$ Bothrops moojeni causou a morte do equino com evolução de $51 \mathrm{~h} 25 \mathrm{~min}$. 0 animal que recebeu a dose de $1 \mathrm{mg} / \mathrm{kg}$ da peçonha de Bothropoides neuwiedi morreu com evolução de 70h41min.

\section{Quadro clínico}

Os sinais clínicos iniciaram-se entre $8 \mathrm{~min}$ e 2h10min após a inoculação. Todos os animais apresentaram inquietação e apatia, arrastar da pinça do membro inoculado no solo quando estimulados a locomover-se, aumento de volume no local da inoculação, que se estendeu por todo o membro inoculado. Em todos os animais esse aumento de volume também se estendia até as regiões torácica, lateral esquerda, abdominal, próximo ao prepúcio (Equinos 3 e 4) e úbere (Equino 6), e no local de coleta de sangue (Equinos 1 e 2). Houve extravasamento de líquido serossanguinolento pela pele íntegra nos locais de aumento de volume e em outras regiões do corpo (pálpebras superiores, região labial e membros). (Fig.1 e 2)

Observou-se secreção hemorrágica nas narinas (Equino 5), hemorragias no local da inoculação (Equino 2), na cavidade oral (Equinos 2 e 5), ao redor dos dentes (Equino 6), no local de coleta de sangue (Equinos 2 e 6), próximo à escápula (Equino 1), próximo à articulação cárpica do membro ante- rior esquerdo (Equinos 1 e 6), na parte distal do membro inoculado (Equinos 2 e 6), além de outros locais com a pele íntegra (Equino 6).

Observou-se ainda mucosa oral congesta (Equinos 2 e 6), pálidas (Equinos 1, 2, 5 e 6) e cianóticas (Equinos 1, 2 e 6). Todos os animais apresentaram vasos episclerais ingurgitados.

À medida que o quadro clínico se agravava, os animais apresentavam tremores musculares, alterações posturais, tentavam aliviar o membro inoculado, relutavam em caminhar e, por vezes cambaleavam. Dois dos animais apresentaram movimentos circulares com o membro estendido (Equinos 1 e 3). Um equino (Equino 1) apresentou soluços frequentes, semelhante a contrações, um ou mais a cada minuto e sensibilidade aumentada ao som.

As frequências cardíaca e respiratória não sofreram alteração. A temperatura retal atingiu $39,3^{\circ} \mathrm{C}$ nos Equinos 2, 4, 6 e $39,4^{\circ} \mathrm{C}$ nos Equinos 1 e 3 . Houve diminuição da temperatura retal na fase final até $36,2,36,5$ e $36,8^{\circ} \mathrm{C}$ nos Equinos 6, 5 e 2 , respectivamente.

Os animais apresentaram diminuição do tônus lingual, diminuição dos reflexos auricular, do lábio superior (Equinos 1, 4 e 6), palpebral (Equinos 1 e 4), palatal e de deglutição (Equino 4). Também foram observados diminuição da sensibili-

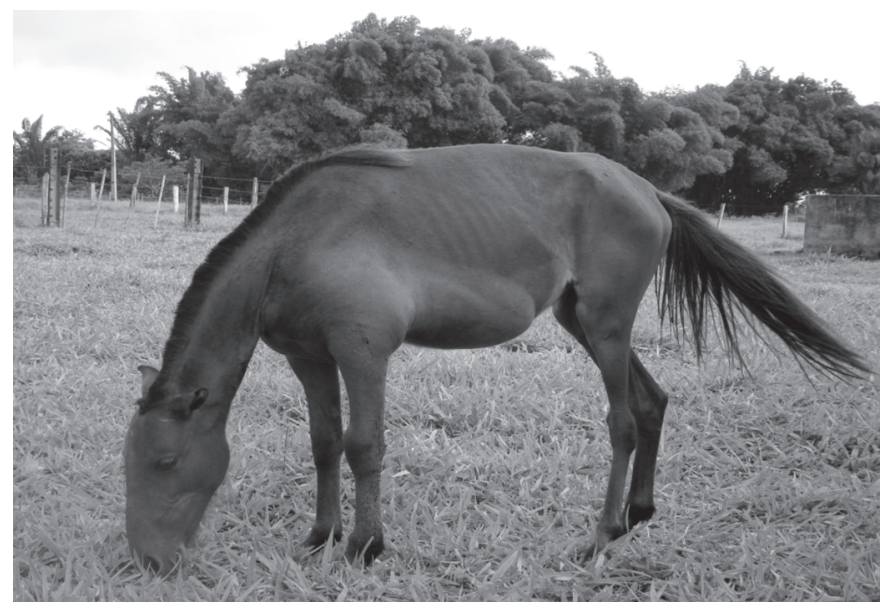

Fig.1. Aumento de volume desde a região do peito até o abdômen do Equino 6 ("Miúda"), inoculado com veneno de Bothropoides neuwiedi).

Quadro 1. Envenenamento botrópico em equinos. Dados principais sobre o delineamento experimental e desfecho

\begin{tabular}{|c|c|c|c|c|c|c|c|}
\hline Animal & Peso & Sexo & $\begin{array}{l}\text { Dose/ } \\
\text { Veneno }\end{array}$ & $\begin{array}{c}\text { Data e hora } \\
\text { da inoculação }\end{array}$ & $\begin{array}{l}\text { Início dos sinais } \\
\text { clínicos após } \\
\text { a inoculação }\end{array}$ & $\begin{array}{l}\text { Tempo de } \\
\text { evolução }\end{array}$ & $\begin{array}{l}\text { Recuperação ou morte } \\
\text { após a inoculação }\end{array}$ \\
\hline $\begin{array}{l}\text { Equino } 1 \\
\text { (Zorro) }\end{array}$ & $130 \mathrm{~kg}$ & Macho & $\begin{array}{l}1 \mathrm{mg} / \mathrm{kg} \\
\text { B. jararaca }\end{array}$ & $\begin{array}{l}24.02 .10 \\
09 \mathrm{~h} 18 \mathrm{~min}\end{array}$ & $08 \mathrm{~min}$ & $59 \mathrm{~h} 07 \mathrm{~min}$ & $\begin{array}{c}\text { Morreu } \\
59 \mathrm{~h} 15 \mathrm{~min}\end{array}$ \\
\hline $\begin{array}{l}\text { Equino } 2 \\
\text { (Fiel) }\end{array}$ & $142 \mathrm{~kg}$ & Macho & $\begin{array}{l}0,5 \mathrm{mg} / \mathrm{kg} \\
\text { B. jararaca }\end{array}$ & $\begin{array}{l}27.02 .10 \\
09 \mathrm{~h} 26 \mathrm{~min}\end{array}$ & $39 \mathrm{~min}$ & $24 \mathrm{~h} 41 \mathrm{~min}$ & $\begin{array}{c}\text { Morreu } \\
\text { 25h20min }\end{array}$ \\
\hline $\begin{array}{l}\text { Equino } 3 \\
\text { (JP Cadilac) }\end{array}$ & $143 \mathrm{~kg}$ & Macho & $\begin{array}{c}1,6 \mathrm{mg} / \mathrm{kg} \\
\text { B. jararacussu }\end{array}$ & $\begin{array}{c}26.02 .10 \\
10 \mathrm{~h} 43 \mathrm{~min}\end{array}$ & $1 \mathrm{~h} 57 \mathrm{~min}$ & 16 dias & Recuperou-se \\
\hline $\begin{array}{l}\text { Equino } 4 \\
\text { (Pé de Pano) }\end{array}$ & $172 \mathrm{~kg}$ & Macho & $\begin{array}{c}0,8 \mathrm{mg} / \mathrm{kg} \\
\text { B. jararacussu }\end{array}$ & $\begin{array}{c}27.02 .10 \\
09 \mathrm{~h} 35 \mathrm{~min}\end{array}$ & $1 \mathrm{~h} 35 \mathrm{~min}$ & 16 dias & Recuperou-se \\
\hline $\begin{array}{l}\text { Equino } 5 \\
\text { (Chocolate) }\end{array}$ & $198 \mathrm{~kg}$ & Fêmea & $\begin{array}{l}0,205 \mathrm{mg} / \mathrm{kg} \\
\text { B. moojeni }\end{array}$ & $\begin{array}{c}26.02 .10 \\
10 \mathrm{~h} 30 \mathrm{~min}\end{array}$ & $2 \mathrm{~h} 10 \mathrm{~min}$ & $51 \mathrm{~h} 25 \mathrm{~min}$ & $\begin{array}{c}\text { Morreu } \\
53 \mathrm{~h} 35 \mathrm{~min}\end{array}$ \\
\hline $\begin{array}{l}\text { Equino } 6 \\
\text { (Miúda) }\end{array}$ & $80 \mathrm{~kg}$ & Fêmea & $\begin{array}{l}1 \mathrm{mg} / \mathrm{kg} \\
\text { B. neuwiedi }\end{array}$ & $\begin{array}{l}27.02 .10 \\
09 \mathrm{~h} 27 \mathrm{~min}\end{array}$ & $15 \mathrm{~min}$ & $70 \mathrm{~h} 41 \mathrm{~min}$ & $\begin{array}{l}\text { Morreu } \\
\text { 70h56min }\end{array}$ \\
\hline $\begin{array}{l}\text { Controle } 1 \\
\text { (Raio) }\end{array}$ & $115 \mathrm{~kg}$ & Macho & $\begin{array}{l}\text { 1ml solução } \\
\text { fisiológica }\end{array}$ & $\begin{array}{l}02.03 .10 \\
14 \mathrm{~h} 08 \mathrm{~min}\end{array}$ & - & - & Sem sintomas \\
\hline $\begin{array}{l}\text { Controle } 2 \\
\text { (Duende) }\end{array}$ & $177 \mathrm{~kg}$ & Macho & $\begin{array}{l}\text { 1ml solução } \\
\text { fisiológica }\end{array}$ & $\begin{array}{c}02.03 .10 \\
14 \mathrm{~h} 01 \mathrm{~min}\end{array}$ & - & - & Sem sintomas \\
\hline
\end{tabular}




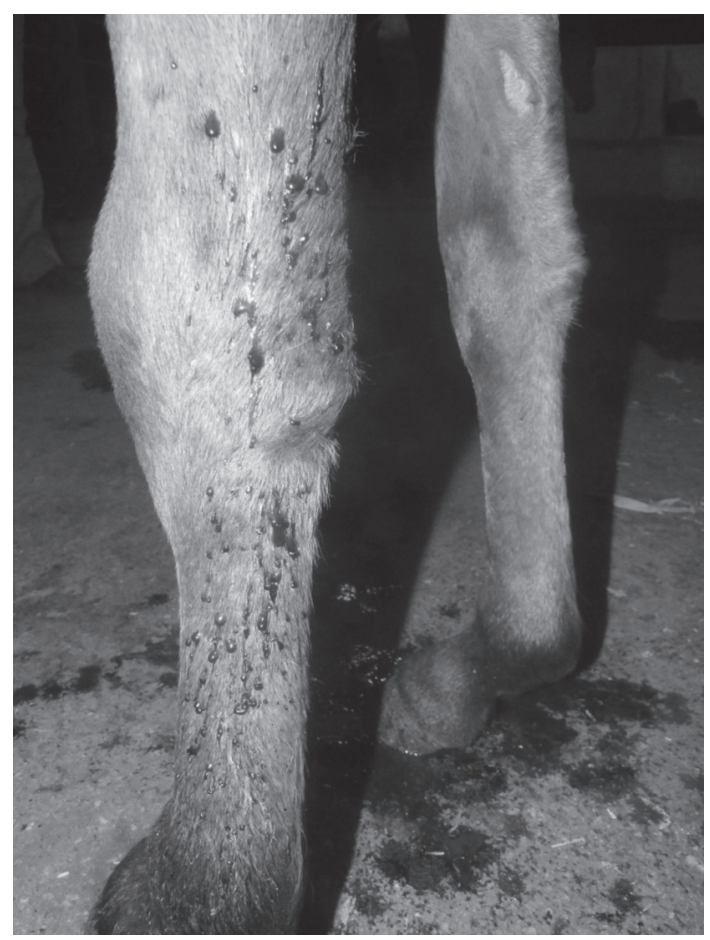

Fig.2. Extravasamento de líquido serossanguinolento pela pele íntegra do membro do Equino 6 ("Miúda"), inoculado com veneno de Bothropoides neuwiedi.

dade cutânea (Equinos 4 e 6), lacrimejamento, bruxismo (Equino 2), nistagmo acentuado e pupila dilatada (Equino 5).

Todos os equinos tinha a motilidade intestinal diminuída e um (Equino 6) apresentou fezes líquidas. Três animais apresentaram urina avermelhada (Equinos 2, 5 e 6) e um poliúria (Equino 5).

$\mathrm{Na}$ fase final os equinos inoculados com o veneno de $B$. jararaca e $B$. neuwiedi caíam com os membros estirados e relinchavam constantemente (Equinos 1, 2 e 6), apresentavam com respiração predominantemente abdominal (Equinos 2 e 6), e logo após morriam. 0 animal inoculado com $B$. moojeni (Equino 5) apresentou dificuldade em se manter em estação e alternava decúbito esternal com decúbito lateral esquerdo, com os membros estirados fazia movimentos de pedalagem, apresentou respiração abdominal e morreu.

Os animais inoculados com o veneno de B. jararacussu recuperaram-se. A extensa tumefação diminuiu gradativamente; do local da inoculação (Equino 4) até a articulação metacárpica (Equino 3) restou uma área flutuante e alopécica, que drenava um líquido de coloração amarelada de consistência fluida a serosa. A limpeza das lesões foi realizada com água e sabão, solução de hipoclorito de sódio a 10\% e repelente local; esse procedimento foi realizado nos dias subsequentes até a cicatrização.

\section{Exames laboratoriais}

Hemograma. Na avaliação do eritrograma verificou-se anemia normocítica normocrômica com progressiva diminuição no número de hemácias, hemoglobina e hematócrito em todos os animais, 24 e 58 horas após a inoculação nos animais inoculados com veneno de B. jararaca, 48 horas após a inoculação nos inoculados com B. jararacussu, 48 horas após a inoculação com B. moojeni e 70 horas após a inoculação com $B$. neuwiedi. Nos leucogramas verificou-se, em todos os equinos, leucocitose por neutrofilia.

Bioquímica sérica. Todos os animais apresentaram aumento nos níveis de ALT, CK, DHL e ureia. Houve aumento nos níveis de creatinina, exceto no Equino 4 e diminuição nos níveis de cálcio em todos os animais.

Glicose sanguínea. Os animais inoculados com o veneno de $B$. jararaca e $B$. neuwiedi apresentaram elevação dos níveis de glicose 24 horas após a inoculação. Nos animais inoculados com B. jararacussu observou-se esta alteração 06 e 12 horas após a inoculação. No animal inoculado com $B$. moojeni verificou-se aumento 12 horas após a inoculação, contudo este aumento não ultrapassou o limite de normalidade.

Urinálise. Na análise das amostras de urina verificou-se proteinúria com a concentração relativa variando de 5 a $300 \mathrm{mg} / \mathrm{dL}$ (traços a 3+), glicosúria com os valores atingindo $1000 \mathrm{mg} / \mathrm{dL}$ e presença de sangue com valores de 50 (Equinos 3 e 6) e 250 eritrócitos/ $\mu$ l (Equino 2).

Avaliação da coagulação sanguínea. Os principais achados da capacidade de coagulação sanguínea estão tabulados no Quadro 2. Em relação à avaliação do tempo de coagulação dos animais submetidos ao envenenamento botrópico, os animais inoculados com o veneno de B. jararaca, no tempo zero, apresentaram tempo de coagulação de 30 e 55 segundos. A partir de seis horas após a inoculação esse tempo variou de 50 a 120 segundos, tornando-se incoagulável 24 horas após a inoculação no Equino 2 (dose 0,5mg/kg) e 59 horas após a inoculção no Equino 1 (dose 1,0mg/kg). Nos animais inoculados com o veneno de B. jararacussu, o tempo de coagulação foi de 22 e 30 segundos no tempo zero, variando de 10 a 163 segundos após a inoculação. 0 animal inoculado com o veneno de B. moojeni, apresentou coagulação no tempo zero de 22 segundos, 48 horas após a inoculação tornou-se incoagulável. No animal inoculado com o veneno de $B$. neuwiedi, o tempo de coagulação foi de 42 segundos no tempo zero, tornando-se incoagulável 48 horas após a inoculação.

\section{Achados de necropsia}

Os achados de necropsia foram extensas hemorragias no tecido subcutâneo, com presença de sangue não coagulado e em boa parte associadas a edema (edema hemorrágico), que se estendia desde o local da inoculação até as regiões cervical, torácica, escapular e membro. Na periferia das áreas hemorrágicas havia predominantemente edema gelatinoso. (4/4) (Fig.3 e 4). Verificou-se grande quantidade de líquido sanguinolento nas cavidades abdominal (2/4) (Fig.5) e torácica (1/ 4) e no saco pericárdico (1/4) (Fig.6), petéquias (3/4) e equimoses no sulco coronário (1/4), sufusões no epicárdio (1/ 4), petéquias (2/4), equimoses (2/4) e hemorragia difusa no endocárdio (1/4) e equimoses no endocárdio da aurícula esquerda (1/4).

Os rins apresentaram superfície com áreas avermelhadas irregulares intercaladas com áreas mais claras ou com superfície semeada de pontilhados vermelhos. Ao corte, o córtex e a medular tinha estriações vermelhas em fundo claro (Fig.7 e 8). Ainda observaram-se edema perirrenal (1/4), 
Quadro 2. Tempos de ativação da protrombina (TAP) e tempo de tromboplastina parcial ativada (TTPA) dos equinos submetidos ao envenenamento botrópico

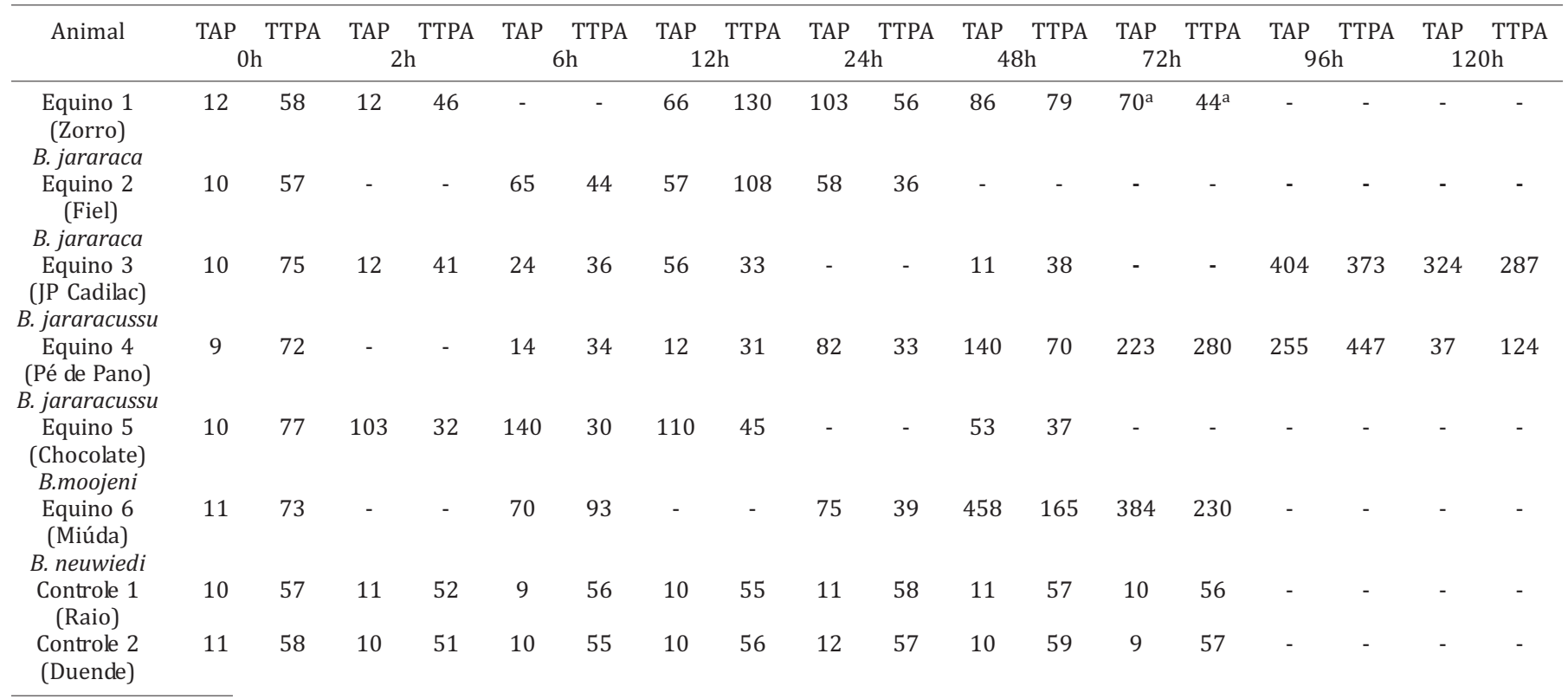

a Equino 1 (Zorro) = esses valores correspondem à última coleta realizada 59 horas após a inoculação.

petéquias na supra-renal com superfície de corte hemorrágica (1/4) e bexiga com petéquias e equimoses (1/4).

Verificaram-se edema na parede do estômago e petéquias e equimoses na mucosa das regiões fúndica e aglandular.
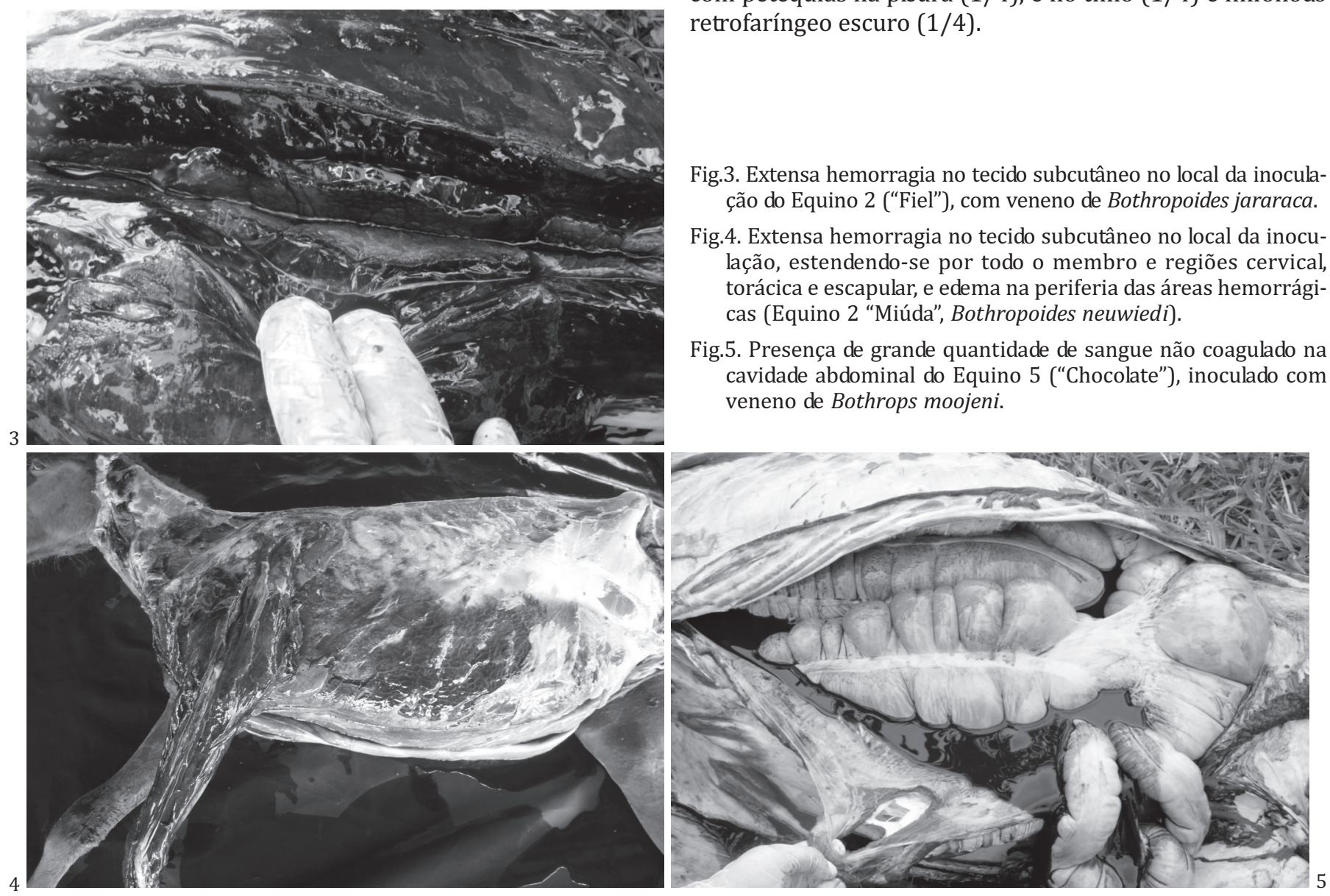

As alças intestinais estavam esbranquiçadas, com petéquias e equimoses na serosa e áreas de hemorragia na mucosa; a avermelhada. Também foi observado pulmão pálido (1/4), com petéquias na pleura (1/4), e no timo (1/4) e linfonodo retrofaríngeo escuro (1/4).

Fig.3. Extensa hemorragia no tecido subcutâneo no local da inoculação do Equino 2 ("Fiel"), com veneno de Bothropoides jararaca.

Fig.4. Extensa hemorragia no tecido subcutâneo no local da inoculação, estendendo-se por todo o membro e regiões cervical, torácica e escapular, e edema na periferia das áreas hemorrágicas (Equino 2 "Miúda", Bothropoides neuwiedi).

Fig.5. Presença de grande quantidade de sangue não coagulado na cavidade abdominal do Equino 5 ("Chocolate"), inoculado com veneno de Bothrops moojeni. cadeia linfática mesentérica estava aumentada de tamanho e 


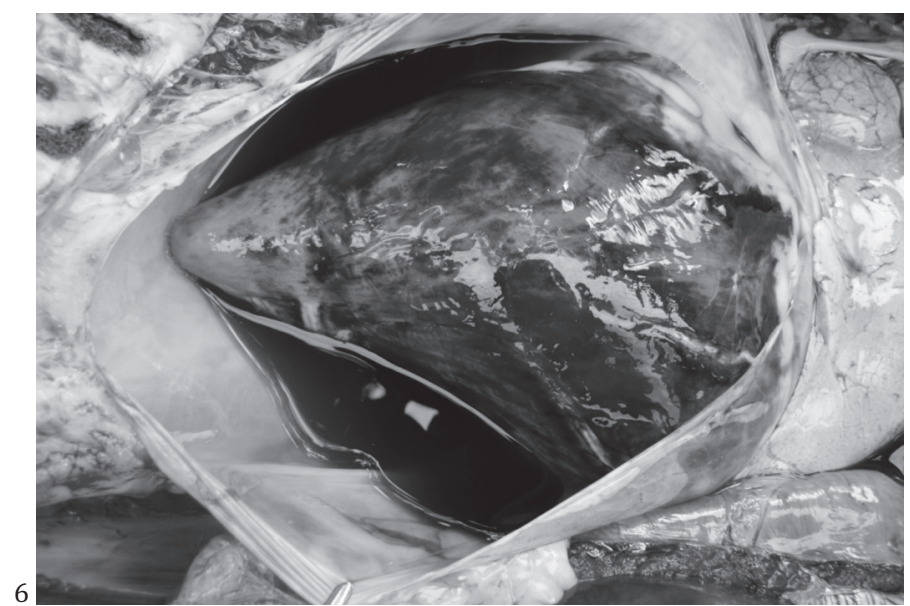

Fig.6. Líquido avermelhado no saco pericárdico e sufusões no epicárdio do Equino 5 ("Chocolate"), inoculado com veneno de Bothrops moojeni.

Fig.7. Rim com pontos avermelhadas do Equino 5 ("Chocolate"), inoculado com veneno de Bothrops moojeni.

Fig.8. Superfície de corte do rim com estriações vermelhos em fundo claro, do Equino 5 ("Chocolate") inoculado com veneno de Bothrops moojeni.

\section{Achados histopatológicos}

Ao exame histopatológico observaram-se no córtex renal, necrose de coagulação nos túbulos uriníferos (1/4), material homogêneo levemente eosinófilo (albumina) na luz dos túbulos uriníferos (2/4) e dilatação dos túbulos uriníferos no córtex e na medular (2/4). No fígado verificou-se leve tumefação dos hepatócitos na periferia dos lóbulos (2/4), hepatócitos com vacuolização discreta e citoplasma discretamente mais vermelho no centro dos lóbulos (1/4). Havia edema na submucosa do intestino que variou de moderado (1/4) a acentuado (2/4).

\section{DISCUSSÃO}

\section{Aspectos toxicológicos e metodologia}

A inoculação foi realizada por via subcutânea, a mesma via utilizada por Caldas et al. (2008), Aragão et al. (2010) e Gomes (2011). Optou-se pela dose de $1 \mathrm{mg} / \mathrm{kg}$ para Bothropoides jararaca, 1,6mg/kg para Bothrops jararacussu e 1mg/ kg para Bothropoides neuwiedi, as mesmas utilizadas em bovinos por Araújo et al. (1963), e 0,205mg/kg para Bothrops moojeni, correspondente à metade da dose utilizada pelo mesmo autor. Para uma evolução mais longa e melhor caracterização do quadro clínico-patológico, reduziu-se a dose de $B$. jararaca e $B$. jararacussu para $0,5 \mathrm{mg} / \mathrm{kg}$ e $0,8 \mathrm{mg} / \mathrm{kg}$, respectivamente.

\section{Quadro clínico geral}

0 aumento de volume no local da inoculação do veneno botrópico, descrito por diversos autores, tanto em casos naturais, quanto em experimentais, também ocorreu em todos os equinos deste estudo, porém, é importante ressaltar que na literatura em geral, esse aumento de volume é descrito como edema. Mas, nos equinos inoculados com a peçonha de $B$. jararaca, B. moojeni e B. neuwiedi, trata-se principalmente
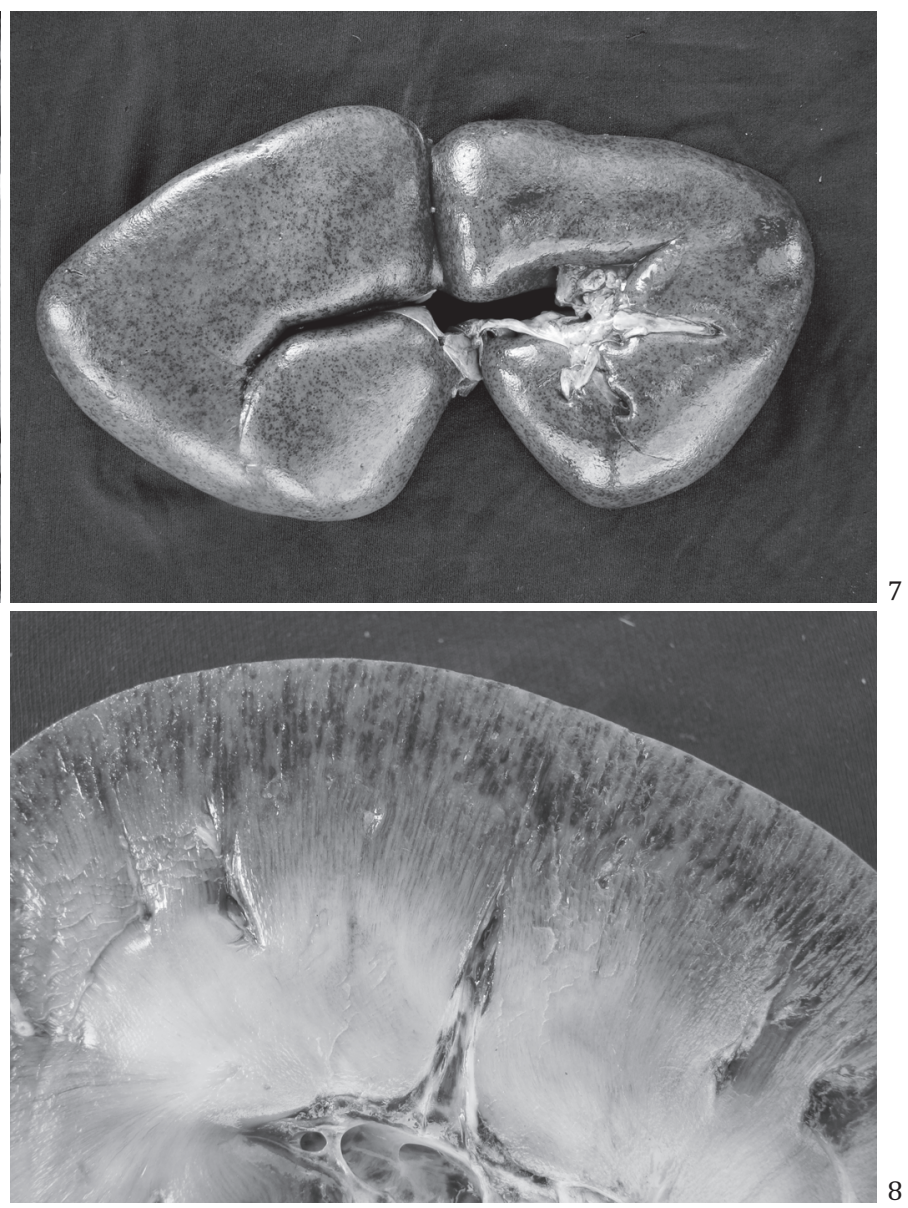

de hemorragia e em parte de edema. Por outro lado não se pode afirmar que o mesmo ocorre com relação a outros ofídios do antigo gênero Bothrops, nem no que se relaciona a outras espécies envenenadas, uma vez que venenos ofídicos, comprovadamente, podem ter efeitos diferentes em diferentes espécies envenenadas. No caso dos equinos do presente experimento, inoculados com B. jararacussu, não se pode verificar o que realmente havia no local do aumento de volume, já que os animais não morreram. Porém suspeita-se de que seja edema, pois no local da inoculação houve diminuição gradativa da tumefação, no qual foi observada uma área alopécica, flutuante, e que drenava um líquido de coloração amarelada de consistência fluida a serosa.

Todos os animais apresentaram sinais de dor como o arrastar da pinça do membro inoculado no solo quando estimulados a locomover-se. Sinais clínicos de dor e grande aumento de volume no local da inoculação do veneno são descritos tanto em casos naturais (Grunert \& Grunert 1969, Menezes 1995/ 96, Méndez e Riet-Correa 2007, WHO 2007), quanto experimentais (Araújo e Belluomini 1960/62, Novaes et al. 1986, Soerensen et al. 1995, Caldas et al. 2008, Aragão et al. 2010) por serpentes do antigo gênero Bothrops, independente da espécie acometida.

Observou-se ainda mucosa oral congesta, tornando-se pálidas a cianóticas, o que pode ser explicado pelo quadro de choque, no qual ocorre vasoconstrição periférica como mecanismo compensatório para aumentar a pressão vascular (McGavin \& Zachary 2009). 


\section{Resultados laboratoriais}

$\mathrm{Na}$ avaliação do eritrograma verificou-se acentuada anemia normocítica normocrômica, ocasionada pelas hemorragias após a inoculação, alteração também descrita em bovinos por Oliveira et al. (2004b) e Caldas et al. (2008) e em ovinos por Aragão et al. (2010) e Gomes (2011). 0 quadro hemorrágico causou acentuada diminuição do número de hemácias, hemoglobina e hematócrito.

O leucograma apresentou leucocitose por neutrofilia, que pode estar associada ao estresse de acordo com McGavin e Zachary (2009) e Smith (2006).

Todos os animais apresentaram aumento nos níveis de ALT, CK, DHL, ureia e glicose. Houve também aumento nos níveis de creatinina, exceto no Equino 4. Os níveis séricos de glicose e ureia sofreram aumento provavelmente, devido ao estresse. Os níveis de CK também se apresentaram aumentados em humanos inoculados por serpentes do antigo gênero Bothrops (França \& Málaque 2009), em camundongos e ratos (Melo \& Suares-Kurtz 1987, Santos et al. 1992, Calil-Elias et al. 2002, Sifuentes et al. 2008) e em bovinos inoculados experimentalmente (Caldas et al. 2008). França \& Málaque (2009) verificaram que em humanos, os níveis de CK e DHL encontravam-se aumentados em pacientes com processo inflamatório no local da picada. Por outro lado, Alencar \& Servaes (1994) verificaram que o aumento de CK também pode ser decorrente de traumatismo muscular e quadro de choque. Em casos de choque, a hipotensão diminui o débito cardíaco e aumenta a produção de lactato, que por sua vez, termina por lesar as fibras musculares; quanto maior o tempo em que o indivíduo fica em choque, maiores serão as lesões tissulares e os níveis de CK (Cecil et al. 2005). 0 acentuado aumento dos níveis de CK também pode ocorrer no decúbito prolongado (Souza Júnior et al. 2007).

A diminuição nos níveis de cálcio observada nos animais pode estar relacionada aos distúrbios da coagulação, já que este é um cofator importante neste processo (Sano-Martins \& Santoro 2003, Graça et al. 2008).

A glicosúria verificada nos animais pode estar associada ao aumento da glicose sanguínea, ocasionada pelo estresse e excitação dos animais. A presença de sangue na urina possivelmente pode ter ocorrido devido à deficiência dos fatores de coagulação, o que pode causar hemorragias espontâneas, incluindo hematúria. A proteinúria na quantidade de traços a $30 \mathrm{mg} / \mathrm{dL}(1+)$ é comumente observada em herbívoros por causa do $\mathrm{pH}$ alcalino, uma reação forte pode indicar extravasamento protéico glomerular grave ou, mais comumente, hemorragia, hemólise ou mioglobinúria (Smith 2006).

0 TAP e TTPA apresentaram-se aumentados em todos os equinos. 0 aumento do TAP pode estar associado à diminuição do nível de fibrinogênio, ao consumo aumentado de protrombina e dos fatores de coagulação V, VII e X (vias extrínseca e comum da coagulação), causado por coagulação intravascular disseminada (CID). Já o aumento de TTPA, provavelmente ocorra devido ao consumo aumentado dos fatores VIII: coagulante (VIII: C), IX, XI e XII (via intrínseca da coagulação), induzido pela CID (Smith 2006).

\section{Achados de necropsia e histopatológicos}

Todos os animais apresentaram grande aumento de volume no local inoculado que se estendia até o membro e região esternal, independente do tipo e dose do veneno. Vários autores empregam a palavra "edema" para definir ou descrever o aumento de volume local, não só em bovinos, mas também em humanos e em outros animais (Araújo et al. 1963, Novaes et al. 1986, Bicudo 1994, Menezes 1995/96, Pérez et al. 1997, Ribeiro e Jorge 1997, Barraviera 1999, Teibler et al. 1999, Méndez \& Riet-Correa 2007). Contudo, tem-se verificado que em casos naturais de envenenamento por B. jararaca em ovinos (Tokarnia et al. 2008) e experimentais por B. alternatus em bovinos (Caldas et al. 2008), por B. jararaca em ovinos (Aragão et al. 2010), por B. moojeni e B. neuwiedi em ovinos (Gomes 2011), que o quadro clínico-patológico era essencialmente hemorrágico, isto é, a tumefação era devido a hemorragias. No presente estudo em equinos que receberam os venenos de B. jararaca, B. moojeni e B. neuwiedi, a tumefação era também devido a hemorragias, porém, em boa parte associadas a edema (edema hemorrágico). Nos equinos inoculados com o veneno de B. jararacussu não foi possível identificar a natureza do aumento de volume.

As desordens hemorrágicas podem ser causadas provavelmente, por degradação dos fatores de coagulação (II, VIII, X) (Nahas et al. 1979, Souza et al. 2000, Cominetti et al. 2003) e comprometimento plaquetário (trombocitopenia).

As alterações regressivas observadas no fígado e rins não foram consideradas significativas e nem relacionadas diretamente ao efeito do veneno botrópico. Lesões semelhantes têm sido observadas em quadros de choque (Jones et al. 1996).

Agradecimentos.- Ao Dr. Aníbal Rafael Melgarejo e a Luis Eduardo Ribeiro da Cunha, Instituto Vital Brazil, Niterói, RJ por terem fornecido os venenos ofídicos de Bothropoides jararaca e Bothrops jararacussu, e à Dra. Paula Helena Santa Rita, da Universidade Católica Dom Bosco, Campo Grande, MS, pelo fornecimento dos venenos ofídicos de Bothrops moojeni e Bothropoides neuwiedi.

\section{REFERÊNCIAS}

Alencar R.A. \& Servaes C.R. 1994. Guia para o Diagnóstico em Medicina Veterinária. Nobel, São Paulo. 205p.

Aragão A.P., Tokarnia C.H., Graça F.A.S., França T.N., Coelho C.D., Caldas S.A. \& Peixoto P.V. 2010. Envenenamento experimental por Bothropoides jararaca e Bothrops jararacussu em ovinos: aspectos clínico-patológicos e laboratoriais. Pesq. Vet. Bras. 30(9):717-728.

Araujo P. \& Belluomini H.E. 1960/1962. Toxicidade de venenos ofídicos. I. Sensibilidade específica de animais domésticos e de laboratório. Mem. Inst. Butantan 30:143-156.

Araújo P., Rosenfeld G. \& Belluomini H.E. 1963. Toxicidade de venenos ofídicos II: doses mortais para bovinos. Arqs Inst. Biológico, São Paulo, 30:43-48.

Barraviera B. 1999. Ofídios: estudos clínicos dos acidentes. EPUB, Petrópolis. 411p.

Bicudo P.L. 1994. Acidentes ofídicos em Medicina Veterinária, p.375-387. In: Barraviera B. (Ed.), Venenos Animais: uma visão integrada. EPUB, Rio de Janeiro.

Caldas S.A., Tokarnia C.H., França T.N., Brito M.F., Graça F.A.S., Coelho C.D. \& Peixoto P.V. 2008. Aspectos clínico-patológicos e laboratoriais do envenenamento experimental por Bothrops alternatus em bovinos. Pesq. Vet. Bras. 28(6):303-312.

Calil-Elias S., Thattassery E., Martinez A.M.B. \& Melo P.A. 2002. Effect of perimuscular injection of Bothrops jararacussu venom on plasma creatine kinase levels in mice: Influence of dose and volume. Braz. J. Med. Biol. Res. 35:1233-1235.

Cecil R.L., Goldman L. \& Ausiello D. 2005. Tratado de Medicina Interna. 22aㅡ ed. Elsevier, Rio de Janeiro. 2776p. 
Cominetti M.R., Ribeiro J.U., Fox J.W. \& Selistre-de-Araujo H.S. 2003. BAG, a new dimeric metalloproteinase/disintegrin from the Bothrops alternatus snake venom that interacts with $\alpha 2 \beta 1$ integrin. Arch. Biochem. Biophys. 416:171-179.

França F.O.S. \& Málaque C.M.S. 2009. Acidente botrópico, p.81-95. In: Cardoso J.L.C., França F.O.S., Wen F.H., Málaque C.M.S. \& Haddad Jr V. (Eds), Animais Peçonhentos no Brasil. 2 $2^{\mathrm{a}}$ ed. Sarvier, São Paulo.

Graça F.A.S., Peixoto P.V., Coelho C.D., Caldas S.A. \& Tokarnia C.H. 2008. Aspectos clínicos e patológicos do envenenamento crotálico experimental em bovinos. Pesq. Vet. Bras. 28(6):261-270.

Gomes A.D. 2011. Aspectos clínico-patológicos e laboratoriais do envenenamento experimental por Bothrops moojeni e Bothropoides neuwiedi em ovinos. Dissertação de Mestrado, Universidade Federal Rural do Rio de Janeiro, Seropédica, RJ.

Grunert E. \& Grunert D. 1969. Beobachtungen von "Bothrops"Schlangenbissverletzungen bei Rind und Pferd in Rio Grande do Sul, Brasilien. Veterinärmedizinische Nachrichten 3:217-232.

Jones T.C. Hunt R.D. \& King N.W. 1996. Veterinary Pathology. $6^{\text {th }}$ ed. Lippincott Williams and Wilkins, Philadelphia. 1392p.

McGavin M.D. \& Zachary J.F. 2009. Bases da Patología em Veterinária. Elsevier, Rio de Janeiro.

Melo P.A. \& Suarez-Krutz G. 1987. Interaction of Bothrops venoms and antivenin on release of creatine kinase from skeletal muscle. Braz. J. Med. Biol. Res. 20(6):821-824.

Méndez M.D.C. \& Riet-Correa F. 2007. Doenças tóxicas: envenamento botrópico, p.31-38. In: Riet-Correa F., Schild A.C., Lemos R. \& Borges J.R.J. (Eds), Doenças em Ruminantes e Equinos. Vol.2. 3를 ed. Varela Editora, São Paulo.

Menezes R.V. 1995/96. Ofidismo em bovinos. Arq. Esc. Med.Vet. UFBA 18(1):24-230.

Nahas L., Kamiguti A.S. \& Barros A.R. 1979. Thrombin-like and factor Xactivator components of Bothrops snake venoms. J. Thromb. Haemost. 41:314-328

Novaes A.P., Lucas S., Abe A.S., Fernandes W., Puorto G. \& Almeida I.L. 1986. Envenenamento botrópico em bovinos: tratamento opcional. Circular Técnica 3, Embrapa-UEPAE São Carlos, São Carlos, SP, p.1-15.

Oliveira N.J.F., Melo M.M., Lara E.R., Lúcia M. \& Lobato Z.I.P. 2007. Perfil clínico e imunológico de bovinos experimentalmente inoculados com veneno bruto e iodado de Bothrops alternatus. Arq. Bras. Med. Vet. Zootec. 59(3):569-576.

Oliveira N.J.F., Melo M.M., Ribeiro E.L., Lago L.A. \& Lucia M. 2004a. Achados histopatológicos em bovinos experimentalmente envenenados com veneno de Bothrops alternatus. XXXI Conbravet, São Luiz, MA. (Resumo)

Oliveira N.J.F., Ribeiro E.L., Silva J.P.G.P., Lago L.A., Lucia M. \& Melo M.M. 2004b. Bovine blood profile after Bothrops alternatus envenenomation. VIII Congr. Soc. Bras. Toxicologia, Angra dos Reis, RJ. (Resumo)
Pérez O.A., Koscinczuk P., Flinta S.M., Maidana H.R. \& Negrette M.S. 1997. Bothrops alternatus envenoming in young dogs. J. Venom. Anim. Toxins 3(1):43-47.

Raposo J.B., Méndez M.C., Baialardi C.E.G. \& Raffi M.B. 2000/2001. Acidente ofídico em equino no sul do Brasil: relato de caso. Revta FZVA, Uruguaiana, 7/8(1):51-57.

Ribeiro L.A. \& Jorge M.T. 1997. Acidente por serpentes do gênero Bothrops: série de 3139 casos. Revta Soc. Bras. Med. Tropical 30(6):475-480.

Sano-Martins I.S. \& Santoro M.L. 2003. Distúrbios hemostáticos em envenenamentos por animais peçonhentos do Brasil, p.289-309. In: Cardoso J.L.C., França F.O.S., Wen F.H., Málaque C.M.S. \& Haddad Jr V. (Eds), Animais Peçonhentos no Brasil: biologia, clínica e terapêutica dos acidentes. Sarvier, São Paulo.

Santos M.C., Gonçalves L.R.C., Fortes-Dias C.L., Cury Y., Gutiérrez J.M. \& Furtado M.F.D. 1992. A eficácia do antiveneno botrópicocrotálico na neutralização das principais atividades do veneno de B. jararacussu. Revta Inst. Med. Tropical 34(2):77-83.

Sifuentes D.N., El-Kik C.Z., Tomaz M.A., Strauch M.A., Ricardo H.D., Calil-Elias S.C., Arruda E.Z., Schwartz E.F. \& Melo P.A. 2008. Ability of sumarin to antagonize the cardiotoxic and some enzymatic activities of Bothrops jararacussu venom. Toxicon 51(1):28-36.

Smith B.P. 2006. Medicina Interna de Grandes Animais. $3^{a}$ ed. Manole, Barueri. 1728p.

Sociedade Brasileira de Herpetologia. Lista Brasileira de Anfíbios e Répteis. Disponível em <http://www.sbhepelologia.org.br/> Acesso 4 nov. 2010.

Soerensen B., Barros A.R., Zezza Neto L., Oliveira A.M., Santos R.V., Messias C.V., Silva A.R.C., Capossoli E.A., Cavalcante N.B.C., Vellucci S.C.C., Repetti E., Santos P.C.G., Pacchini C.E. \& Alves Júnior M. 1995. Aspecto clínico e laboratorial do envenenamento botrópico e crotálico em bovinos. Unimar Ciências 4(2):28-33.

Souza D.H.F., Iemma M.R.C., Ferreira L.L., Faria J.P., Oliva M.L.V., Zingali R.B., Niewiarowski S. \& Selistre-de-Araujo H.S. 2000. The disintegrin-like domain of the snake venom metalloprotease alternagin inhibits $\alpha 2 \beta 1$ integrinmediated cell adhesion. Arch. Biochem. Biophys. 384(2):341-350.

Souza Júnior A.A., Aragão A.P., Rousso Filho R., Caldas S.A., Souza A.M. \& Graça F.A.S. 2007. Análise bioquímica de bovinos submetidos ao decúbito experimental. Revta Univ. Rural, Sér. Ciênc. Vida 27:580-582.

Teibler P., Pérez O.A., Maruñaque S., Ruiz R., Koscinczuk P., Sánchez Negrette M. \& Mussart de Coppo N. 1999. Lesiones locales y sistemicas inducidas por veneno de Bothrops alternatus (víbora de La Cruz) de Argentina. Acta Toxicol. Argent. 7(1):7-10.

Tokarnia C.H. \& Peixoto P.V. 2006. A importância dos acidentes ofídicos como causa de mortes em bovinos no Brasil. Pesq. Vet. Bras. 26:55-68.

Tokarnia C.H., Brito M.F., Malafaia P. \& Peixoto P.V. 2008. Acidente ofídico em ovinos causado por Bothrops jararaca. Pesq. Vet. Bras. 28(12):643-648.

WHO 2007. Rabies and envenomings: A neglected public health issue. World Health Organization, Geneva. 38p. 